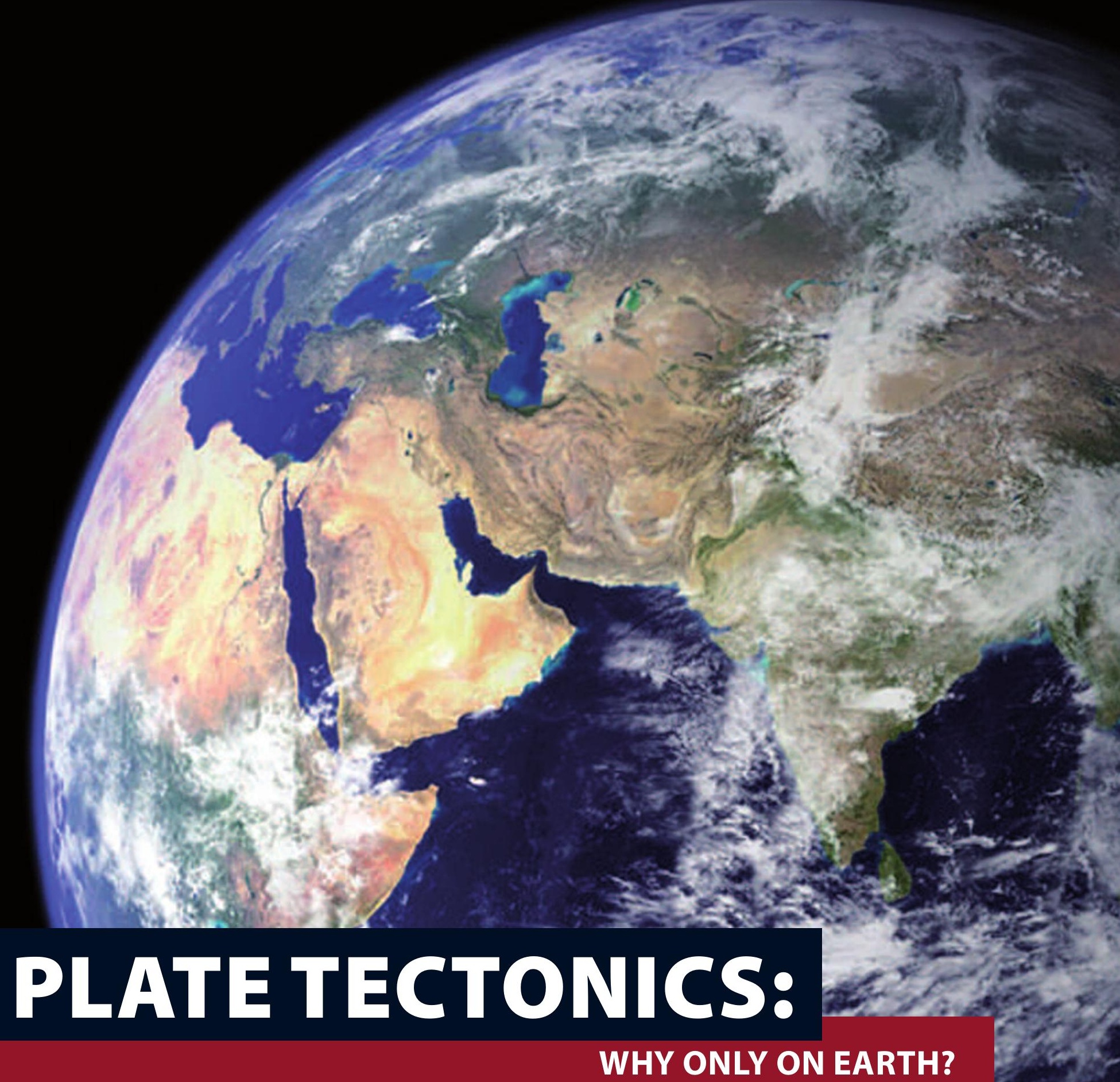

* Hans Keppler * Bayerisches Geoinstitut, Universität Bayreuth, 95440 Bayreuth * DOI: 10.1051/epn/2009604

The uppermost layer of the solid Earth, the lithosphere, is believed to consist of mechanically rigid plates that move on a softer layer in Earth's mantle. Plate tectonics can explain most of the features and processes operating on the surface of our planet. Where plates collide, for example, mountain ranges form. 
4 P.27: Earth as seen from space. Image: NASA/GSFC"

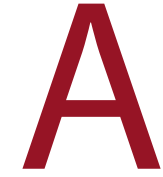
t some other places, the oceanic lithosphere dives back into the Earth's mantle. These subduction zones are also causing volcanic activity; the "ring of fire" surrounding the Pacific Ocean is a prominent example. In turn, new lithosphere is produced at the middle oceanic ridges by volcanic processes.

There is little doubt that the concept of plate tectonics describes how the Earth operates now and how it operated in the last few hundred million years. A more difficult question is, how far plate tectonics reaches back in Earth's 4.6 billion years of history. There is increasing geochemical evidence, however, that plate tectonics was established very early in Earth's history, perhaps already within the first billion years. Therefore, it is rather surprising that none of the other terrestrial planets - Mercury, Mars and Venus - show any sign of plate tectonics today or in their geologic history. Plate tectonics causes surface features on a planet that can be easily recognized by remote sensing, even without detailed geological sampling. The elevation of Earth's surface has a pronounced bimodal distribution, with most of the continents being approximately $1 \mathrm{~km}$ above sea level and most of the ocean bottoms being approximately $4 \mathrm{~km}$ below sea level. Elevations between those extremes or exceeding them are rare. This bimodal distribution is a direct consequence of plate tectonics, corresponding to the difference in composition of the continental and oceanic crust, which again can be traced back to the difference in the melting processes occurring below middle oceanic ridges and in subduction zones. There is nothing like this on any other known planet and other indicators of plate tectonics are also missing. So, why does plate tectonics only exist on Earth?

\section{The importance of the asthenosphere}

Earth's mantle is solid, because observations of earthquakes show that it transmits elastic shear waves. However, the rocks and minerals of the mantle apparently can be plastically deformed over geologic time, so that over very long time scales, the mantle behaves like an extremely viscous liquid. This was actually known already more than a century ago, long before the advent of plate tectonics. The continuous uplift of Scandinavia by several $\mathrm{mm}$ per year that can be observed today is a response to the disappearance of the load of the glaciers at the end of the ice age, and suggests a liquid-like behavior of the material below the lithosphere. Convection in Earth's mantle

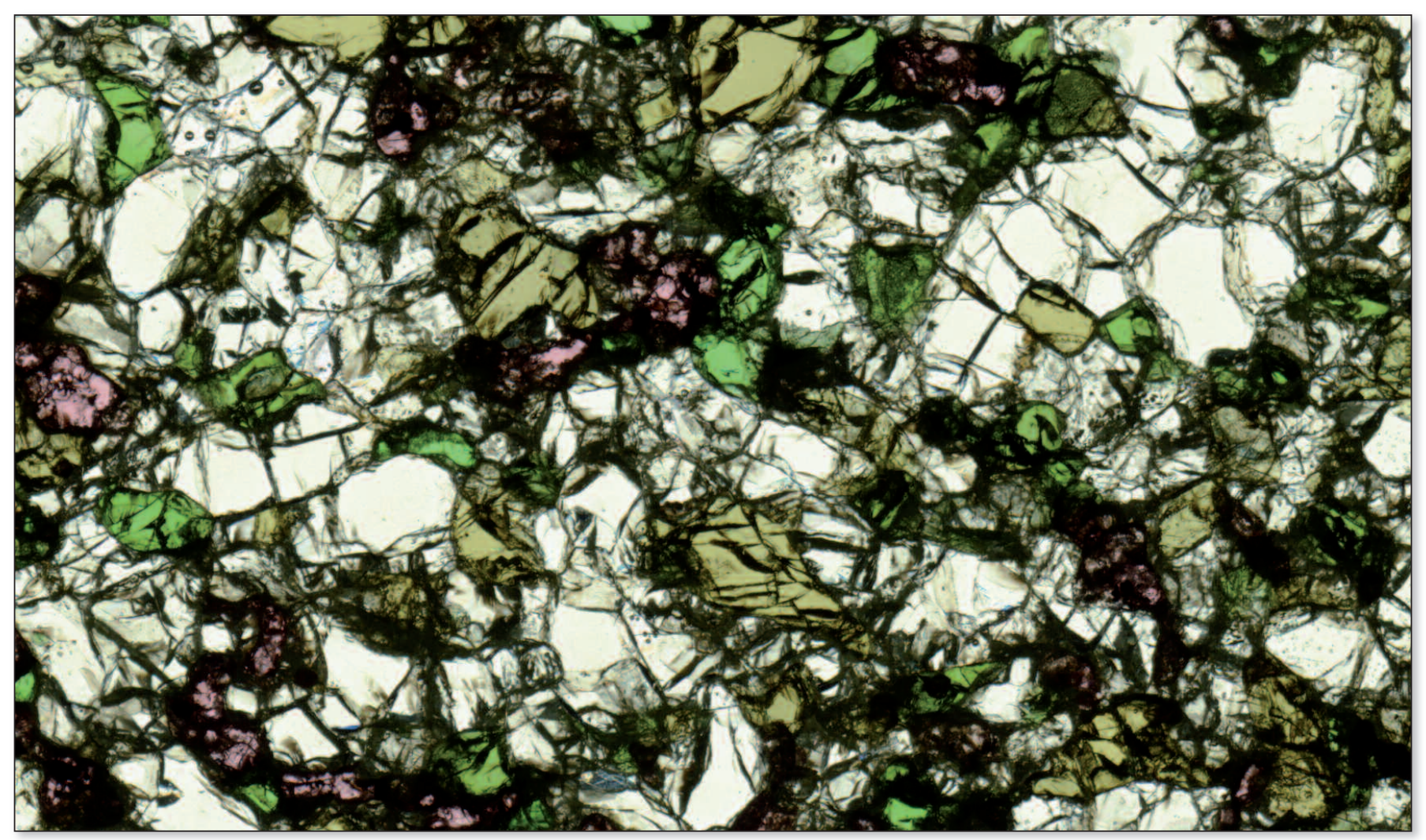

$\Delta$ FIG. 1: Thin section of a mantle xenolith, a piece of the Earth's mantle brought to the surface by a volcanic eruption. The almost colorless grains are olivine $(\mathrm{Mg}, \mathrm{Fe})_{2} \mathrm{SiO}_{4}$, brown is enstatite $(\mathrm{Mg}, \mathrm{Fe}) \mathrm{SiO}_{3}$, intense green is diopside, $\mathrm{Cr}$-bearing $\mathrm{CaMgSi}_{2} \mathrm{O}_{6}$, and red is garnet $\left(\mathrm{Mg}_{1} \mathrm{Fe}\right)_{3} \mathrm{Al} \mathrm{I}_{2}\left(\mathrm{SiO}_{4}\right)_{3}$. $\mathrm{All}_{\mathrm{mineral}}$ formulae are simplified; in particular, enstatite and diopside contain some Al as well. Grain size is about $1 \mathrm{~mm}$. Sample from Pali-Aike, Patagonia; photograph courtesy of Sylvie Demouchy, CNRS Montpellier. 
by solid-state deformation of rocks is what ultimately drives plate motions on Earth's surface. The energy source for this convection is partially radioactive decay, partially heat retained from the origin of the Earth. Geodynamic models of mantle convection can correctly reproduce many features of plate motions in the last several hundred million years. Interestingly, these models show that it is quite difficult to get a style of geologic activity similar to plate tectonics. Over a wide range of parameters, most models either yield planets with a rigid lithosphere or planets without any stable lithosphere. In order to get something that looks like plate tectonics, apparently a channel of low viscosity below the lithosphere is required. There is independent evidence for the existence of such a channel on Earth. Seismic measurements show that between a depth of about $60 \mathrm{~km}$ and $220 \mathrm{~km}$ below the oceans, the velocities of elastic shear and compression waves are reduced, indicating a reduced bulk and shear modulus, i.e., the presence of softer material. Under continents, the upper boundary of this "seismic low-velocity zone" is depressed to $150 \mathrm{~km}$ depth. The seismic low-velocity zone is therefore often identified with the asthenosphere, the mechanically weak layer in the mantle that allows the movement of plates. But why is the asthenosphere so weak?

It was often believed that the transition from the rigid lithosphere to the asthenosphere is a purely thermal boundary. As temperature increases with depth, the mechanical strength of rocks should decrease. However, recent seismic data indicate an extremely sharp boundary between the lithosphere and the asthenosphere, with major changes in seismic velocities occurring over just a few kilometers [1]. This cannot be explained by a gradual change in temperature; rather, this observation implies a phase change, some modification in the mineralogy of the mantle. Moreover, a gradual increase in temperature cannot explain why the asthenosphere apparently also has a lower boundary - temperature keeps increasing towards the center of the Earth. Understanding the origin of Earth's asthenosphere is therefore probably the key to understanding why plate tectonics exists on Earth, but not on other planets, such as Venus. Venus is in size, mass and composition almost a twin of Earth. But why is the geology of Venus so different? One obvious observation is that there is hardly any water on Venus - the surface is hot, with a dense $\mathrm{CO}_{2}$-rich atmosphere; water has been lost to space by a runaway greenhouse effect. Could the particular tectonic style on Earth be somehow related to the presence of water?

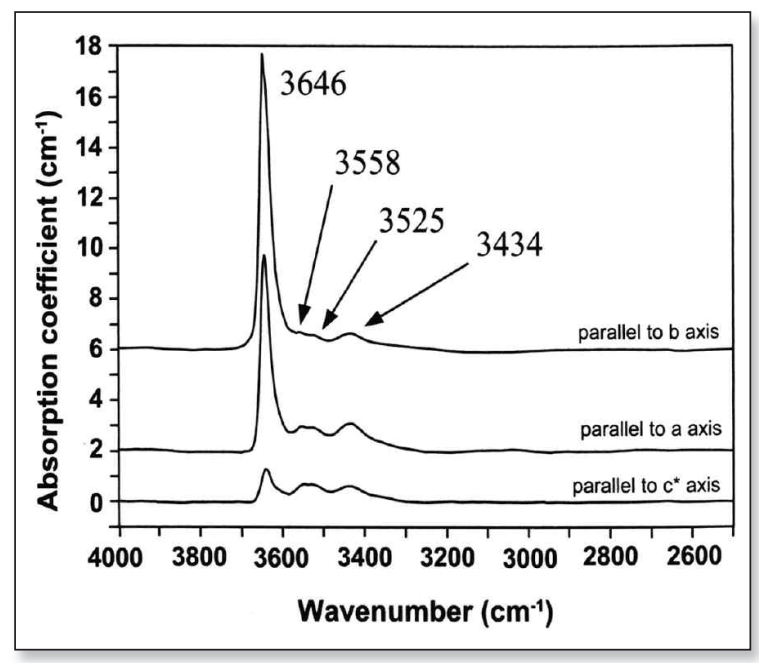

\section{Water in Earth's mantle}

Earth's upper mantle consists of silicates such as olivine $(\mathrm{Mg}, \mathrm{Fe})_{2} \mathrm{SiO}_{4}$, enstatite $(\mathrm{Mg}, \mathrm{Fe}) \mathrm{SiO}_{3}$, and diopside $\mathrm{CaMgSi}_{2} \mathrm{O}_{6}$ that do not contain any water in their chemical formula. For this reason, it was believed for a long time that nearly all of the water in our planet is in the oceans and that the mantle is essentially dry. Violent volcanic eruptions sometimes bring pieces of mantle rocks up to the surface (Fig. 1). Accurate chemical analyses of minerals from such samples often appeared to show traces of water. However, this was usually dismissed as a surface contamination or inclusions of foreign material. This view slowly changed in the 1960 's, when a few mineralogists started to look at such samples by infrared spectroscopy. This method is very sensitive to traces of molecular water or $\mathrm{OH}$ groups. Moreover, it can also provide data on the chemical environment of the protons $\left(\mathrm{H}^{+}\right)$in a material. If polarized infrared radiation is used, infrared absorption will be strongest when the $\mathrm{OH}$ dipole is parallel to the electrical field vector, while no absorption occurs if the $\mathrm{OH}$ dipole and the electrical field vector are perpendicular to each other. Studies of gem-quality, optically clear oriented single crystals of mantle minerals by infrared spectroscopy showed that these minerals always contain traces of water in the form of $\mathrm{OH}$ groups with a defined orientation relative to the crystallographic axes (Fig. 2). This cannot be random impurities. Apparently, some water is chemically dissolved in these mantle minerals as $\mathrm{OH}$ point defects [2]. The concentrations do not appear to be spectacular - a few hundred to a few thousand of ppm, or 0.01 to 0.1 wt. \%. However, integrated over the enormous mass of the mantle, these minerals constitute a water reservoir comparable in size to the mass of all oceans. Moreover, the traces of water drastically change the physical properties of minerals. Already $1000 \mathrm{ppm}$ or $0.1 \mathrm{wt}$ \% of water dissolved as $\mathrm{OH}$ defects in the crystal lattice reduce the creep strength of olivine
4 FIG. 2:

Polarized infrared absorption spectra of a diopside (Cr-bearing $\mathrm{CaMgSi}_{2} \mathrm{O}_{6}$ ) crystal. All bands correspond to $\mathrm{OH}$ point defects in different structural environments in the crystal. From the dependence of infrared absorbance on the direction of the electric field vector, the orientation of the $\mathrm{OH}$ group in the crystal can be determined. From [5]. 
"u by three orders of magnitude [3]. This is probably because the incorporation of protons produces cation vacancies, which enhance the mobility of dislocations. Numerical models suggest that this reduction of mantle viscosity by traces of water dissolved in the crystal lattice is one prerequisite for the development of plate tectonics. But can water also explain the channel of low viscosity in Earth's asthenosphere?

\section{Earth, the water planet}

Water drastically reduces the melting point of silicates. At 1 bar, dry basalt would melt around $1200^{\circ} \mathrm{C}$. However, in the presence of $10 \%$ water, and if the confining pressure is high enough to prevent the water from escaping from the system, the melting point drops to $800^{\circ} \mathrm{C}$ or less.

\section{Traces of water in minerals drastically reduce their mechanical strength} This is because water is highly soluble in silicate melts. Also, even a very small fraction of melt in a rock can reduce its creep strength and viscosity drastically. At the same time, the velocities of elastic shear waves and compression waves would be reduced, consistent with the seismic observations for the asthenosphere. The temperatures in the asthenosphere are too low to allow melting in the absence of water. However, with some water present, melting may be possible. But if the presence of melt is restricted to the asthenosphere, what could be the reason? Is perhaps the water content in the asthenosphere higher than in the rest of the mantle? Considering the efficient convective mixing of the entire mantle, this appears to be unlikely.

Recently, a new model has been proposed [4] that elegantly explains the formation of partial melt in Earth's

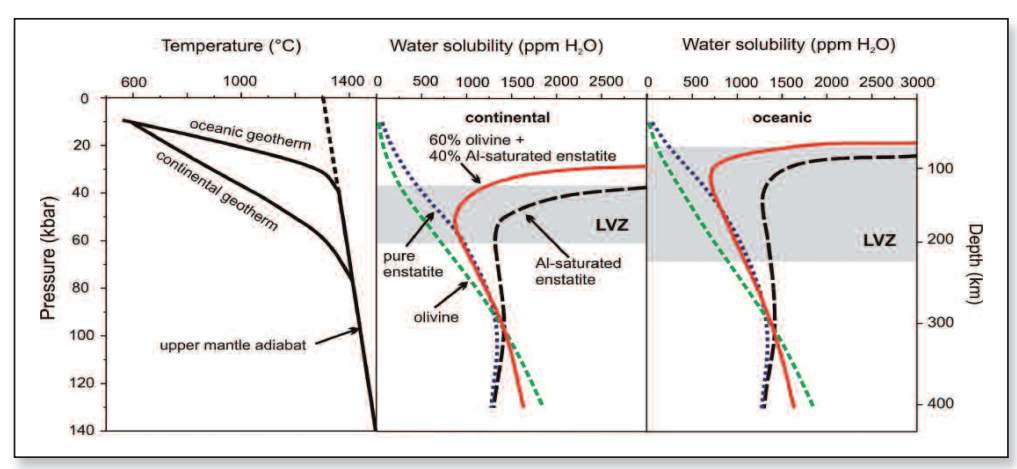

$\Delta$ FIG. 3: Water solubility in minerals of the Earth's mantle. The bulk water solubility (red curve) is a weighed average of the water solubility in olivine (green) and Al-bearing enstatite (black). The bulk water solubility has a pronounced minimum at the depths interval of the asthenosphere, corresponding to the seismic low velocity zone (LVZ, gray shaded). In this region, not all water can be stored in the solid minerals anymore; the excess water causes partial melting. By the presence of a small amount of melt, the mechanical strength of the rock is greatly reduced. The model correctly predicts the different depths of the asthenosphere below continents and oceans due to the differences in the temperature profiles (left). From [4]. asthenosphere (Fig. 3). Among the minerals of the upper mantle, olivine and Al-bearing enstatite are the main hosts of water. Experimental studies show that the solubility of water as $\mathrm{OH}$ defects in olivine continuously increases with pressure and temperature, and therefore with depth in the mantle. However, the water solubility in enstatite sharply decreases with depth. This different behaviour is due to differences in the substitution mechanism responsible for water incorporation. In olivine, two protons substitute for $\mathrm{Mg}^{2+}$; the resulting cation vacancy makes the crystal more compressible. Accordingly, water dissolution is favored at high pressure. In enstatite, however, $\mathrm{H}^{+}+\mathrm{Al}^{3+}$ substitute for $\mathrm{Si}^{4+}$. This causes an expansion of the crystal lattice and therefore, water solubility drops at high pressure. The different behaviour of olivine and enstatite produces a pronounced minimum of water solubility in a depth interval in the mantle corresponding exactly to the seismic low velocity zone. At this depth, not all water can be dissolved in the solid minerals anymore. The excess water forms a partial melt. By the presence of a small fraction (about $1 \%$ ) of partial melt, the strength of the rock is greatly reduced. The model correctly predicts the different depth of the seismic low-velocity zone below continents and oceans; it also correctly predicts that the upper boundary of this zone should be very sharp, while the lower boundary is more gradual (compare the red curve in Fig.3).

It therefore appears that the formation of an asthenosphere and therefore the existence of plate tectonics are only possible in a planet with a water-bearing mantle, consistent with the absence of plate tectonics on Venus. Earth is the water planet - not only because of its oceans, but also because of its tectonic style.

\section{About the Author}

Hans Keppler studied mineralogy and chemistry at the University of Karlsruhe (Germany), where he also obtained his $\mathrm{Ph}$. D. He was a research fellow at the California Institute of Technology. After some time at the Bayerisches Geoinstitut in Bayreuth and the University of Tübingen, he returned to Bayerisches Geoinstitut in 2004 as a Professor of Experimental Geophysics. Since 2007 , he is also the director of this institute.

\section{References}

\section{[1] C.A. Rychert et al., Nature 436, 542 (2005).}

[2] H. Keppler and J.R. Smyth, Water in nominally anhydrous minerals (Mineralogical Society of America, Chantilly, 2006).

[3] S.J. Mackwell et al., J. Geophys. Res. 90, 11319 (1985).

[4] K. Mierdel et al., Science 315, 364 (2007).

[5] G. Bromiley et al., Am. Mineral. 89: 941 (2004). 